2

3

4

5

6

7

8

9

10

\title{
Acute toxicity of mercury to Daphnia magna under different conditions
}

\author{
Martin T. K. Tsui and Wen-Xiong Wang
}

3 supplementary information, 3 tables and 1 figure

11 


\section{Supplementary Information I - Measurement of HSP concentrations.}

12 The frozen tissue sample was first thawed, to which $0.5 \mathrm{ml}$ of $0.25 \mathrm{M}$ sucrose buffer (BDH, 13 Poole, UK) was added to the pre-weighed daphnids and the soft tissues were homogenized 14 using an ultrasonic homogenizer in ice bath. The homogenates were centrifuged at 16,000 $\mathrm{g}$ 15 for $20 \mathrm{~min}$ at $4{ }^{\circ} \mathrm{C}$ and the supernatants were transferred into a new microcentrifuge tube, to 16 which $0.3 \mathrm{ml}$ of $0.5 \mathrm{M}$ glycine buffer (Sigma, St. Louis, MO, USA) and $0.5 \mathrm{ml}$ of $20 \mu \mathrm{g} \mathrm{Ag}$ $17 \mathrm{ml}^{-1}$ (Sigma) spiked with a radiotracer $\left({ }^{110 \mathrm{~m}} \mathrm{Ag}\right.$ at $3.7 \mathrm{kBq} \mathrm{ml}^{-1}$, from Ris $\varnothing$ National Laboratory, 18 Roskilde, Denmark) were added. The mixture were agitated and incubated for 10-20 min at 19 room temperature. The HSP binding sites were saturated with Ag in the solution within 10 20 min, and excess Ag was removed by adding $0.1 \mathrm{ml}$ of rabbit red blood cell haemolysate, 21 heating $\left(5 \mathrm{~min}\right.$ at $\left.100{ }^{\circ} \mathrm{C}\right)$ and centrifuging $(5,000 \mathrm{~g}$ for $5 \mathrm{~min})$ the samples for three times. 22 For the third addition, the supernatant was spun at $16,000 \mathrm{~g}$ for $5 \mathrm{~min}$. The final supernatant 23 was separated and radioassayed for ${ }^{110 \mathrm{~m}} \mathrm{Ag}$, and the HSP concentrations in the daphnids were 24 calculated as $3.55 \times$ of the Ag concentrations measured in the samples and expressed as $\mathrm{mg}$ $25 \mathrm{~kg}^{-1}$ wet wt (i.e., $1 \mu \mathrm{g}$ of Ag binds to $3.55 \mu \mathrm{g}$ of HSP or MTLP). 
27 Supplementary Information II - Flowchart of procedures in subcellular fractionation of the

28 tissue sample and the generation of a total of four subcellular fractions.

29

30

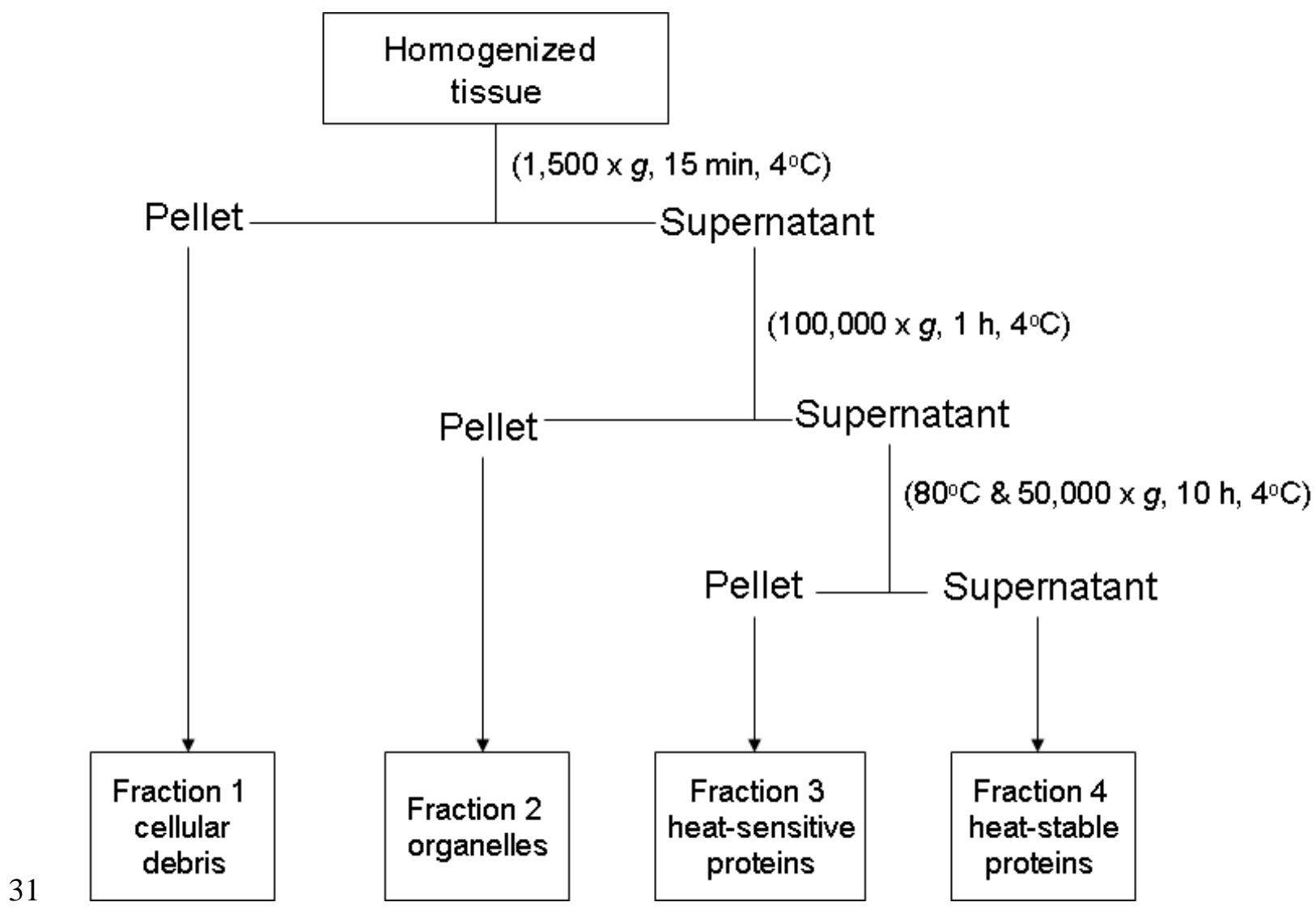


32 Supplementary Information III - Estimation of maximal Hg concentrations using Michaelis-

\section{Menten kinetics}

34 In order to estimate the maximum concentrations of $\mathrm{Hg}$ (or number of binding sites of $\mathrm{Hg}$ on D. magna) that accumulated in the daphnids under different conditions, Michaelis-Menten

36 type kinetics based on the measured $\mathrm{Hg}$ body burdens under varying ambient $\mathrm{Hg}$

37 concentrations were simulated with the following equation:

38

39

$$
\left[\mathrm{Hg}_{\mathrm{T}}\right]=\left[\mathrm{Hg}_{\mathrm{T}}\right]_{\max } \times\left[\mathrm{Hg}_{\mathrm{W}}\right] /\left(\mathrm{K}_{\mathrm{d}}+\left[\mathrm{Hg}_{\mathrm{W}}\right]\right)
$$

40

41 where $\left[\mathrm{Hg}_{\mathrm{T}}\right]$ is the $\mathrm{Hg}$ body burden, $\left[\mathrm{Hg}_{\mathrm{T}}\right]_{\max }$ is the maximal $\mathrm{Hg}$ body burden, $\left[\mathrm{Hg}_{\mathrm{W}}\right]$ is the 42 aqueous $\mathrm{Hg}$ concentration, and $\mathrm{K}_{\mathrm{d}}$ is the aqueous $\mathrm{Hg}$ concentration to reach half-maximal 43 saturation of $\mathrm{Hg}$ body burden. 
44 Table S1 Estimated parameters from Michaelis-Menten type kinetics for $\mathrm{Hg}$ accumulation in

45 D. magna under different conditions. Note: $r^{2}=$ correlation coefficient, $\left[\mathrm{Hg}_{\mathrm{T}}\right]_{\max }=$ the

46 estimated maximal $\mathrm{Hg}$ body burden and $\mathrm{K}_{\mathrm{d}}=$ the aqueous $\mathrm{Hg}$ concentrations to reach half-

47 maximal saturation. Error bars indicate the standard errors of the means. Note: $\infty=$ infinity.

\begin{tabular}{lllll}
\hline Treatment & Variable & $r^{2}$ & $\begin{array}{l}{\left[\mathrm{Hg}_{\mathrm{T}}\right]_{\max }} \\
\left(\mathrm{mg} \mathrm{kg}^{-1} \text { wet wt. }\right)\end{array}$ & $\begin{array}{l}\mathrm{K}_{\mathrm{d}} \\
\left(\mu \mathrm{g} \mathrm{l}^{-1}\right)\end{array}$ \\
\hline Temperature & $10{ }^{\circ} \mathrm{C}$ & 0.880 & $17.5 \pm 3.5$ & $18.0 \pm 9.9$ \\
& $24{ }^{\circ} \mathrm{C}$ & 0.981 & $50.6 \pm 8.9$ & $52.0 \pm 13.7$ \\
Population & $32{ }^{\circ} \mathrm{C}$ & 0.961 & $\infty$ & $\infty$ \\
& $\mathrm{CAS}$ & 0.981 & $50.6 \pm 8.9$ & $52.0 \pm 13.7$ \\
Body size & $\mathrm{CBSC}$ & 0.978 & $31.4 \pm 19.6$ & $50.3 \pm 45.6$ \\
& LFS & 0.977 & $59.0 \pm 20.4$ & $55.5 \pm 29.4$ \\
& $2.4 \mathrm{~mm}$ & 0.981 & $50.6 \pm 8.9$ & $52.0 \pm 13.7$ \\
& $2.9 \mathrm{~mm}$ & 0.983 & $\infty$ & $\infty$ \\
& $3.2 \mathrm{~mm}$ & 0.984 & $39.1 \pm 12.0$ & $112 \pm 47.6$ \\
& No PE & 0.981 & $50.6 \pm 8.9$ & $52.0 \pm 13.7$ \\
& PE I & 0.974 & $47.1 \pm 8.4$ & $36.5 \pm 12.1$ \\
& PE II & 0.983 & $93.4 \pm 35.0$ & $99.3 \pm 52.7$ \\
& PE III & 0.916 & $27.2 \pm 3.8$ & $10.3 \pm 6.7$
\end{tabular}

48

49 
49 Table S2 Heat-stable protein (HSP) concentrations and percentage of $\mathrm{Hg}$ associated with

50 HSP in D. magna under different conditions. Values in the parentheses represent the standard

51 deviation of three individual measurements and the standard error of the means for HSP and

$52 \mathrm{Hg}$ in HSP, respectively. Means for a variable within a treatment are not significantly

53 different $(p>0.05)$ if they bear the same letter.

\begin{tabular}{llll}
\hline Treatment & Variable & $\begin{array}{l}\text { HSP } \\
\left(\mathrm{mg} \mathrm{kg}^{-1} \text { wet wt. }\right)\end{array}$ & $\begin{array}{l}\mathrm{Hg} \text { in HSP } \\
(\%)\end{array}$ \\
\hline Temperature & $10^{\circ} \mathrm{C}$ & $22.2(2.98)^{\mathrm{a}}$ & $31.6(3.73)$ \\
& $24{ }^{\circ} \mathrm{C}$ & $25.2(3.71)^{\mathrm{a}}$ & $41.0(2.86)$ \\
Population & $32^{\circ} \mathrm{C}$ & $58.1(4.94)^{\mathrm{b}}$ & $35.0(5.15)$ \\
& CAS & $25.2(3.71)^{\mathrm{a}}$ & $41.0(2.86)$ \\
Body size & CBSC & $29.9(0.72)^{\mathrm{b}}$ & $38.4(1.88)$ \\
& LFS & $24.6(2.98)^{\mathrm{a}}$ & $25.7(0.00)$ \\
Pre-exposure & $2.4 \mathrm{~mm}$ & $25.2(3.71)^{\mathrm{b}}$ & $41.0(2.86)$ \\
& $2.9 \mathrm{~mm}$ & $13.7(0.40)^{\mathrm{a}}$ & $39.8(1.48)$ \\
& $3.2 \mathrm{~mm}$ & $39.2(5.37)^{\mathrm{c}}$ & $46.3(0.55)$ \\
& No PE & $25.2(3.71)^{\mathrm{a}}$ & $41.0(2.86)$ \\
& PE I & $32.6(7.04)^{\mathrm{a}}$ & $51.5(3.41)$ \\
& PE II & $25.6(20.7)^{\mathrm{a}}$ & $48.0(1.75)$ \\
& PE III & $101(10.6)^{\mathrm{b}}$ & $43.1(4.26)$
\end{tabular}

54 


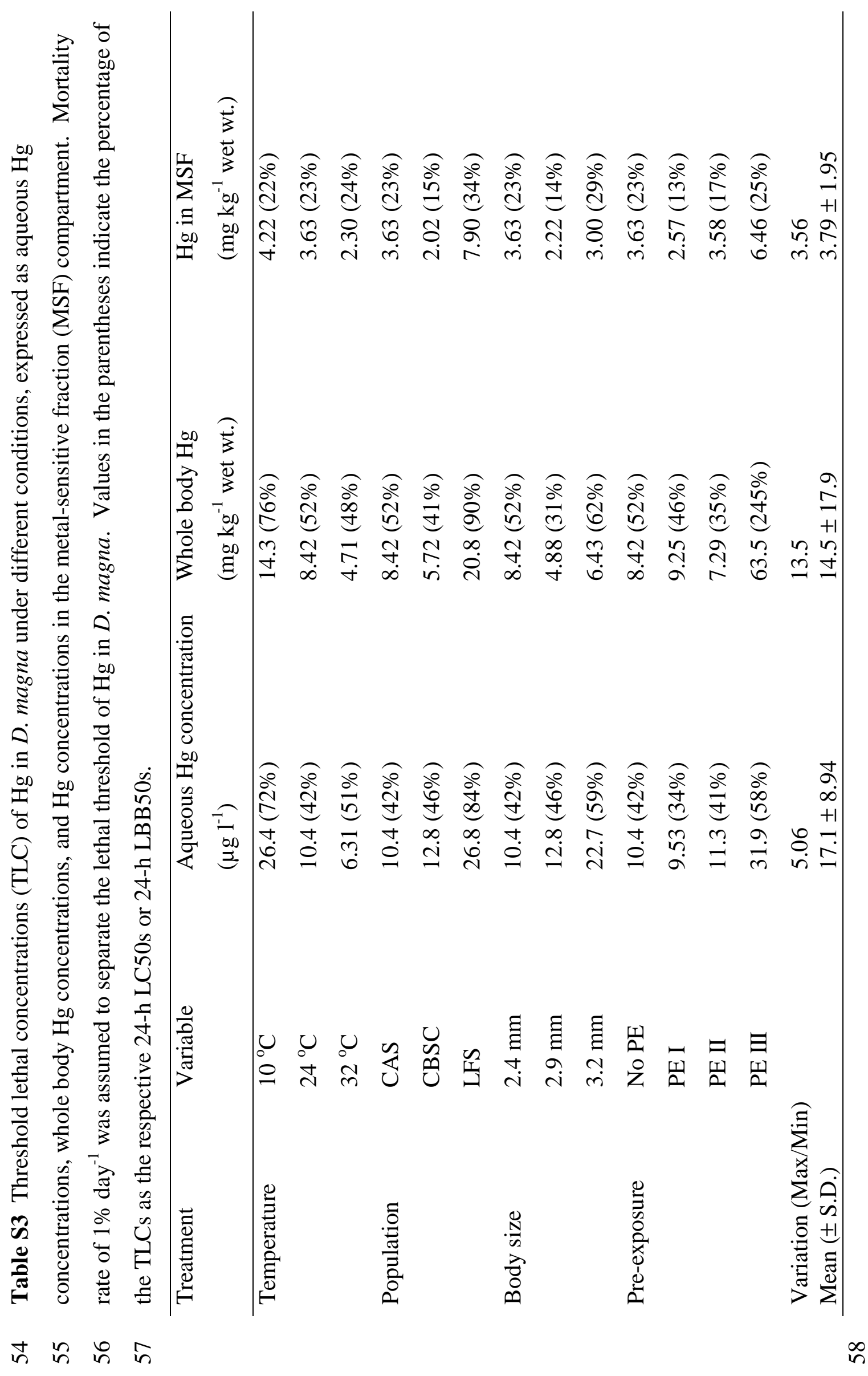



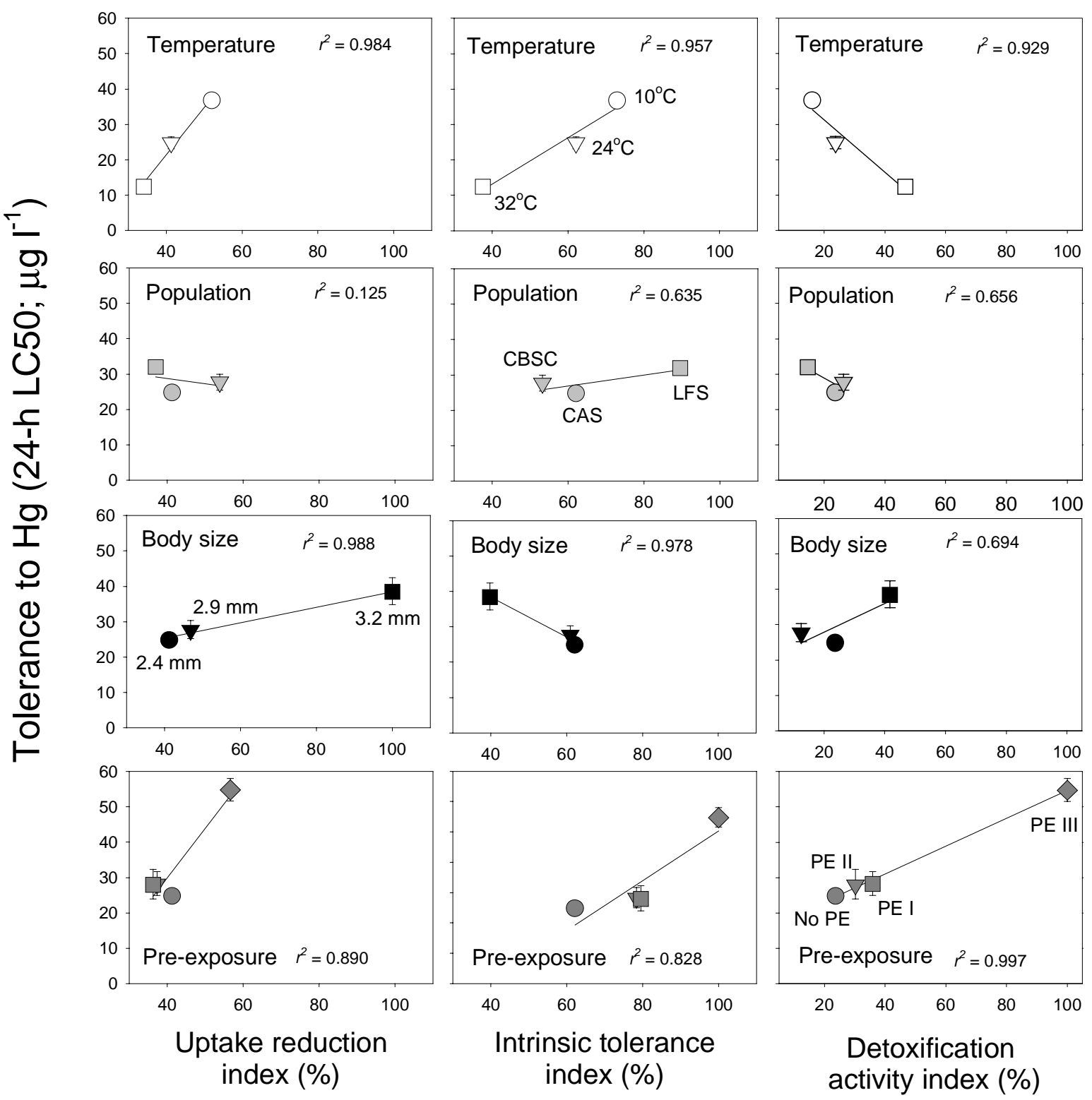

59

60 Fig. S1 Relationships between the 24-h LC50s of Hg to D. magna and the indices of different

61 tolerance mechanisms, including uptake reduction, enhancement of intrinsic tolerance and

62 increase of detoxification activity conditions. 